\title{
Asymptomatic Aortic Stenosis - Prognosis, Risk Stratification and Follow-Up
}

\author{
Paoli Ursula and Dichtl Wolfgang \\ Medical University Innsbruck, Internal Medicine III / Cardiology, \\ Austria
}

\section{Introduction}

Due to an aging population and improved non-invasive cardiac imaging (mainly the wide use of transthoracic echocardiography), the number of patients with asymptomatic aortic stenosis (AS) is continuously increasing. Aortic stenosis is a progressive active disease which can be treated effectively by aortic valve implantation. Therefore, optimal timing of surgery is crucial demanding precise risk stratification to identify high-risk but still asymptomatic patients. Such patients should undergo close clinical follow-up examination or even elective aortic valve replacement.

Whereas severe symptomatic aortic stenosis is a class I indication for valve replacement, the decision to operate on asymptomatic patients remains controversial. Accepted indications for aortic valve replacement for asymptomatic patients with severe aortic stenosis are (a) the need of cardiac surgery for any other reason such as coronary bypass grafting or surgery of the aorta ascendens and (b) if left ventricular systolic dysfunction defined by an ejection fraction below $50 \%$ occurs.

The risk of sudden death in asymptomatic severe aortic stenosis without preceding symptoms is a matter of concern, although it is regarded as low (around 1\% per year) and below the perioperative mortality of aortic valve replacement. Otherwise, there is a risk of irreversible myocardial damage due to left ventricular hypertrophy and myocardial fibrosis if surgery is performed too late.

The strategy to wait for occurrence of symptoms before indicating aortic valve implantation is further challenged by an increased mortality in patients awaiting surgery after onset of symptoms, by late symptom reporting by many patients and a higher operative risk for more symptomatic patients.

On the other hand, the immediate operative risk, the long-term morbidity and mortality related to the prosthetic aortic valve, and the potential need for re-operation have to be taken into account.

Several risk factors for worse clinical outcome in patients with asymptomatic aortic stenosis have been established in the last years. Hemodynamic parameters such as a peak aortic jet velocity $>5 \mathrm{~m} / \mathrm{s}$ or a mean gradient $>60 \mathrm{mmHg}$ are used to define very severe aortic stenosis, and an increase in peak aortic jet velocity $>0.3 \mathrm{~m} / \mathrm{s} /$ year define a fast hemodynamic progression rate. Whether such high- risk patients should undergo elective aortic valve implantation even in the asymptomatic state is still a matter of debate and handled differently between European and American Guidelines. Furthermore, interest has 
shifted to exercise tolerance, degree of valve calcification, the influence of gender or systemic parameters such as natriuretic peptides. Among these new non-hemodynamic parameters, exercise-induced symptoms are the best validated criterion so far.

Some patients with aortic stenosis have a reduced stroke volume despite preserved left ventricular ejection fraction (referred to as paradoxical low flow aortic stenosis). These patients suffer from more pronounced left ventricular concentric remodelling, smaller left ventricular cavity, increased global left ventricular load, and reduced midwall shortening. They often present with a low transvalvular gradient even though they have a severe stenosis on the basis of valve area, and this situation may lead to an underestimation of stenosis severity and an underutilization of valve replacement.

It remains a clinical challenge to balance risk between watchful waiting and early aortic valve implantation in patients with asymptomatic aortic stenosis. The physician managing these patients has to "look at the valve, listen to the patient" (C. Otto). The decision of aortic valve replacement should be taken by cardiologists who "look globally, think globally" (P. Pibarot, JG. Dumesnil).

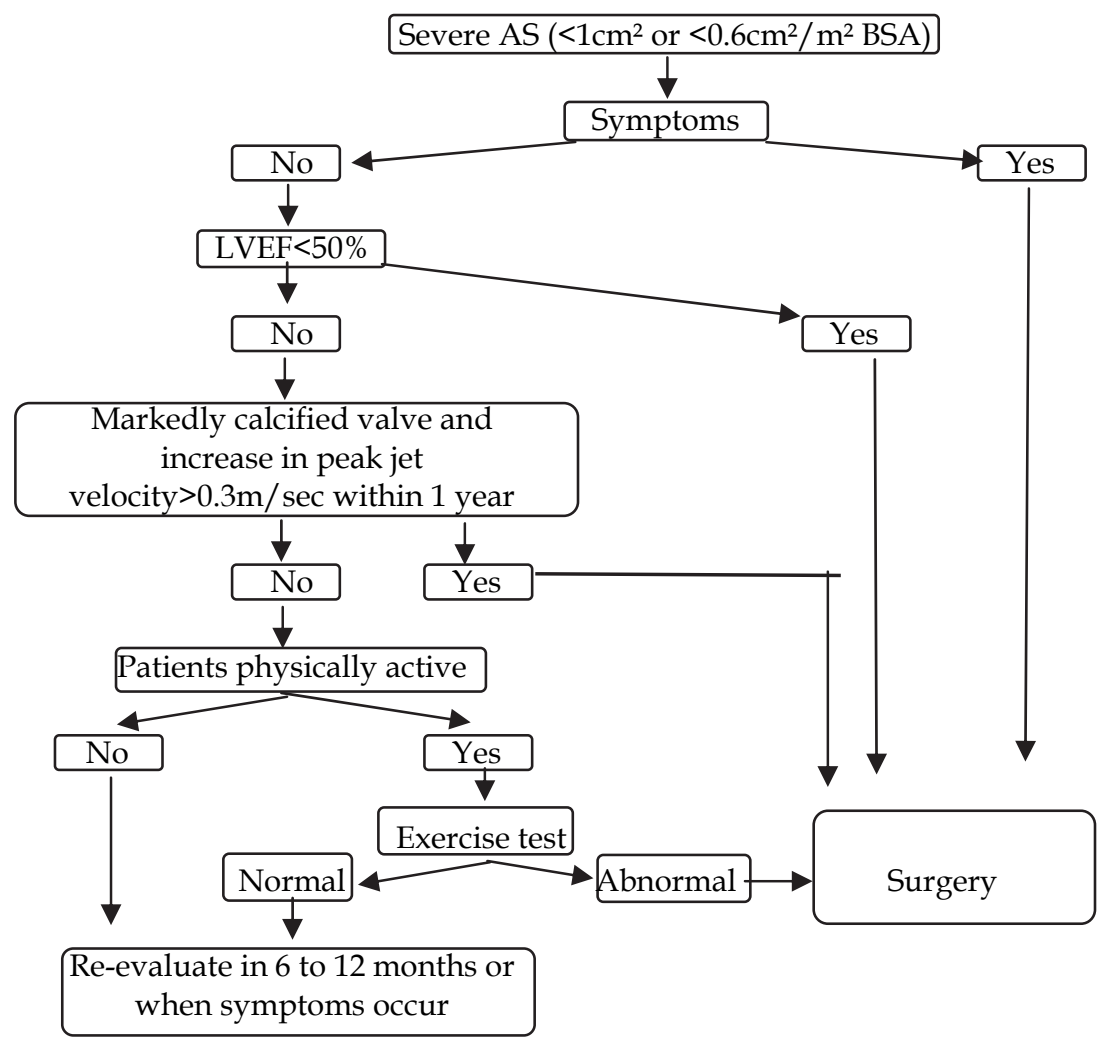

Fig. 1. Management of patients with severe aortic stenosis (AS). BSA denotes body surface area; EF denotes ejection fraction; LV denotes left ventricle (Vahanian \& Otto, 2010). 


\section{Assessment of aortic stenosis}

\subsection{History}

Aortic stenosis proves the outstanding diagnostic power of a well-taken clinical history. Classical symptoms of aortic stenosis are angina pectoris, heart failure, severe cardiac arrhythmia such as ventricular tachycardia and syncope. However, these symptoms are often preceded by a decreased exercise tolerance or dyspnoe on exertion. It is the skill and clinical experience of the physician to discover and interpret these changes correctly in patients who may have a low physical activity also for other reasons (e.g. frailty, pulmonary disease, obesity, de-conditioning).

Patients with congenital valvular stenosis may give a history of a murmur since childhood or infancy. Those with rheumatic stenosis may have a history of rheumatic fever. The influence of sex on the outcome of asymptomatic aortic stenosis is a matter of debate as well. Some studies found that female gender is independently predictive of the midterm development of symptoms (Monin et al., 2009), but guidelines recommendations so far do not differ between genders.

\subsection{Physical findings}

As usual, anamnesis is followed by physical examination. Typical for aortic stenosis is a systolic ejection murmur, with a maximum in the $2^{\text {nd }}$ ICR right parasternal with radiation in the carotids. In patients with a loud systolic murmur, an echocardiography is indicated. Arterial hypertension is present in many patients and imposes additional load on the left ventricle by increased vascular resistance. This results in lower transvalvular gradients and possible underestimation of stenosis severity, whereas clinical symptoms might occur earlier.

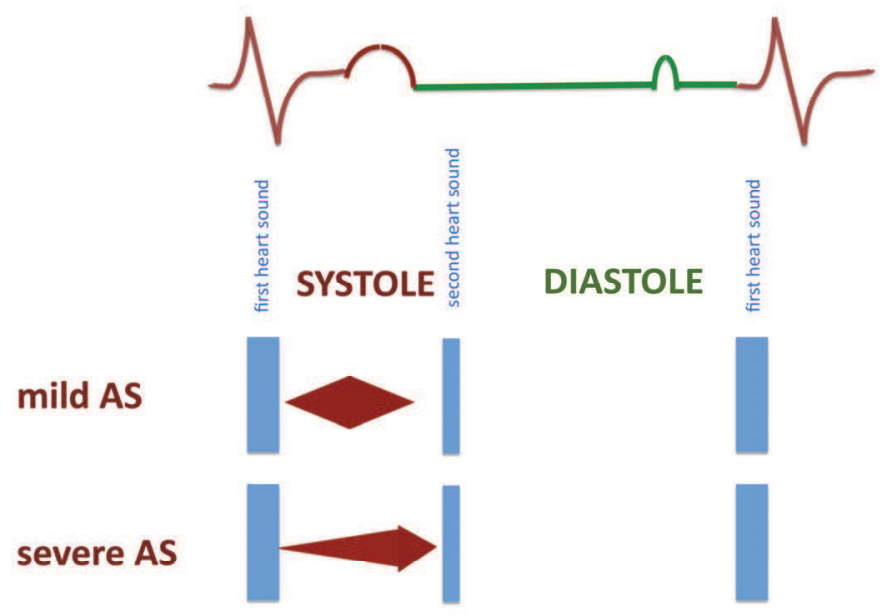

Fig. 2. Systolic murmurs in mild and severe aortic stenosis.

\subsection{Echocardiography}

Transthoracic echocardiography supplies the most important information for risk stratification of adults with aortic stenosis yielding information about valve anatomy and 
hemodynamics, the left ventricular response to chronic pressure overload, aortic dilatation and associated valve disease. Only in certain circumstances, a transoesophageal or a 3Dechocardiography is needed, e.g. for improved analysis of valve anatomy (bicuspid valve, planimetry of valve area) or preoperative measurements needed in transcatheter aortic valve implantation (TAVI).

On 2D echocardiography, a stenotic aortic valve is thickened and calcified, with restricted opening of the cusps. Three basic parameters are routinely used to assess the hemodynamic severity of aortic stenosis: jet velocity, mean transaortic pressure gradient and valve area. The aortic jet velocity is measured with continuous wave Doppler from several transducer windows, to obtain the signal most parallel with the direction of stenotic jet flow yielding the highest velocity signal (Figure 2). For this, color-flow imaging may be helpful to guide Doppler beam alignment. Sometimes it is necessary that the patient has to move to a rightsupine position using a right parasternal window and a smaller nonimaging continuouswave Doppler transducer (so-called pencil-probe) which is easier to manipulate between the ribs. In very small or very tall adults, valve area should be indexed for body size, e.g. to avoid that a small person with only a moderate obstruction get the misdiagnosis of a severe aortic stenosis.

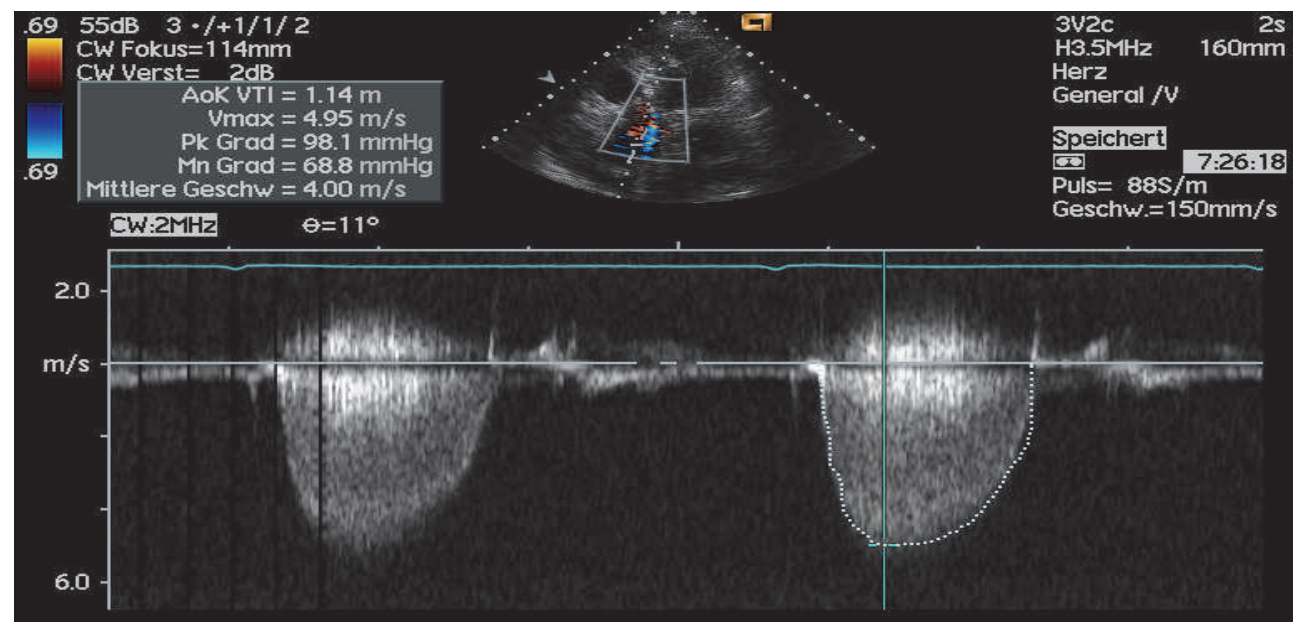

Fig. 3. Using an apical five-chamber view, transvalvular continuous Doppler shows a severe to very severe aortic stenosis, with mean/peak systolic gradients of 69 and $98 \mathrm{mmHg}$, respectively, and a peak systolic velocity of $4.9 \mathrm{~m} / \mathrm{s}$.

There are some caveats in the assessment of aortic stenosis by transthoracic echocardiography. The measurement of the left ventricular outflow tract diameter has to be thoroughly performed from a systolic freeze-frame in the parsternal long-axis view, defined by the distance from where the anterior (right aortic) cusp meets the ventricular septum to the point where the posterior (noncoronary) cusp meets the anterior mitral leaflet. This may be difficult because of heavy calcifications. Furthermore, in patients with atrial fibrillation or flutter, velocities should be averaged from 5 to 10 cardiac cycles.

Whereas systolic left ventricular dysfunction occurs very late in the disease process (mainly in symptomatic patients with very severe aortic stenosis who do not undergo valve 
replacement for whatever reason), left ventricular diastolic dysfunction is frequently found in an early phase of aortic stenosis. Left ventricular hypertrophy can be found in most cases of severe aortic stenosis.

\section{NORMAL}
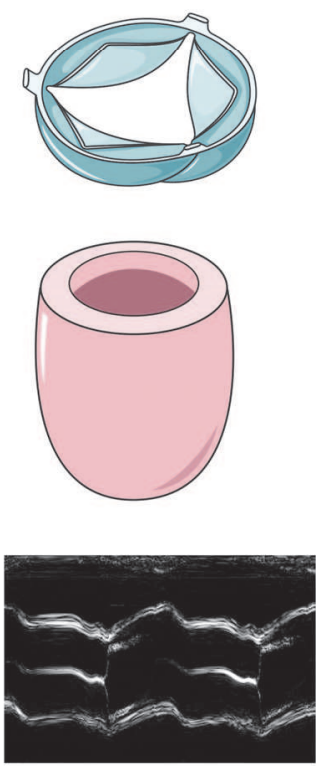

AORTIC STENOSIS

pressure overload

concentric hypertrophy

valvular calcification

restricted cusp movement
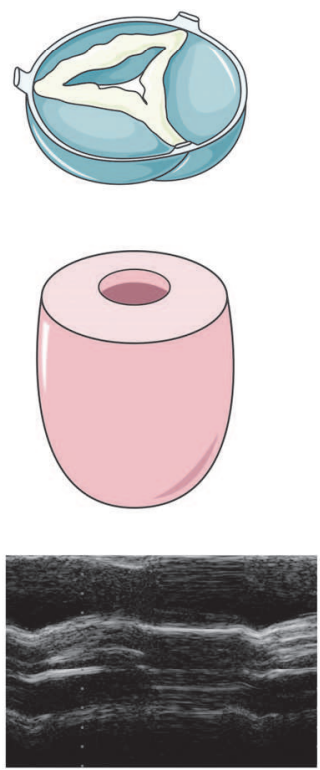

Fig. 4. Left ventricular hypertrophy and restricted aortic cusp movement.

Four echo parameters permit the classification of aortic stenosis severity. Unfortunately, the European Society of Cardiology (ESC) and the American College of Cardiology/ American Heart Association (ACC/AHA) differrently interpret mean gradients, as shown in Table 1 (values in brackets are advised from ACC/AHA). A shortcoming of this classification is that one patient may fall in two different categories, e.g. if he has an aortic jet velocity from 3.1 and an AVA from $1.6 \mathrm{~cm}^{2}$. Notably, guidelines are based on physiological valve area, as measured by continuity equation, which differs from anatomical valve area.

Additional echo parameters who are not yet used in clinical routine are stroke-work loss and left ventricular strain analysis. Stroke-work loss is the ratio of mean gradient and left ventricular pressure, and a stroke-work loss $>26 \%$ results in a major clinical event rate $>$ $30 \%$ within the following three months (Bermejo et al., 2003).

Patients with systolic dysfunction and small valve area present with low transvalvular gradients. It is important to differentiate those with a low gradient due to low stroke volume 


\begin{tabular}{|l|l|l|l|l|l|}
\hline & Aortic sclerosis & Mild AS & Moderate AS & Severe AS & $\begin{array}{c}\text { Very } \\
\text { severe AS }\end{array}$ \\
\hline $\begin{array}{l}\text { Aortic jet velocity } \\
(\mathrm{m} / \mathrm{s})\end{array}$ & $<2.6$ & $2.6-3.0$ & $3.0-4.0$ & $>4.0$ & $>5.0$ \\
\hline $\begin{array}{l}\text { Mean gradient } \\
(\mathrm{mmHg})\end{array}$ & - & $<30(25)$ & $30-50(25-40)$ & $>50(40)$ & $>60$ \\
\hline AVA $\left(\mathrm{cm}^{2}\right)$ & - & $>1.5$ & $1.0-1.5$ & $<1.0$ & $<0.6$ \\
\hline $\begin{array}{l}\text { Indexed AVA } \\
\left(\mathrm{cm}^{2} / \mathrm{m}^{2}\right)\end{array}$ & - & $>0.9$ & $0.6-0.9$ & $<0.6$ & - \\
\hline
\end{tabular}

Table 1. Categories of aortic stenosis severity, according to ESC (Vahanian et al., 2007) and ACC/AHA (Bonow et al., 2008) guidelines.

\begin{tabular}{|c|c|c|}
\hline Severe asymptomatic AS & ESC & $\mathrm{ACC} / \mathrm{AHA}$ \\
\hline $\mathrm{EF}<50 \%$ & \multicolumn{2}{|l|}{ IC } \\
\hline $\begin{array}{l}\text { Undergoing CABG, aortic surgery or mitral valve } \\
\text { surgery }\end{array}$ & \multicolumn{2}{|l|}{$\mathrm{IC}$} \\
\hline $\begin{array}{l}\text { Exercise test } \\
-\quad \text { symptoms } \\
-\quad \text { fall in BP to below baseline } \\
\text { complex ventricular arrhythmias }\end{array}$ & $\begin{array}{l}\text { IC } \\
\text { IIaC } \\
\text { IIbC }\end{array}$ & $\begin{array}{l}\mathrm{IIbC} \\
\mathrm{IIbC} \\
/\end{array}$ \\
\hline $\begin{array}{l}\text { Predictors of rapid progression (moderate to severe valve } \\
\text { calcification, rate of } v_{\max } \text { increase } \geq 0.3 \mathrm{~m} / \mathrm{s} / \text { year }\end{array}$ & $\mathrm{IIaC}$ & / \\
\hline $\begin{array}{l}\text { Predictors of rapid progression (age, valve calcification, } \\
\text { CAD) or if surgery might be delayed at symptom onset }\end{array}$ & / & $\mathrm{IIbC}$ \\
\hline $\begin{array}{l}\text { Severe left ventricular hypertrophy }(>15 \mathrm{~mm}) \text { without } \\
\text { arterial hypertension }\end{array}$ & $\mathrm{IIbC}$ & / \\
\hline $\begin{array}{l}\text { Extremly severe AS (AVA }<0.6 \mathrm{~m}^{2}, \mathrm{v}_{\max }>5 \mathrm{~m} / \mathrm{s}, \Delta \mathrm{P}_{\text {mean }} \\
>60 \mathrm{mmHg} \text { ) and operative risk }<1 \%\end{array}$ & / & $\mathrm{IIbC}$ \\
\hline Moderate asymptomatic AS & ESC & $\mathrm{ACC} / \mathrm{AHA}$ \\
\hline Hemodynamically unstable & \multicolumn{2}{|c|}{$\begin{array}{l}\text { AVR (IB); BAV (IIbC) as } \\
\text { bridge to surgery }\end{array}$} \\
\hline \multicolumn{3}{|l|}{ Indeterminate severity of AS } \\
\hline $\begin{array}{l}\text { Low-gradient AS with left ventricular dysfunction and } \\
\text { contractile reserve }\end{array}$ & $\mathrm{IIaC}$ & / \\
\hline $\begin{array}{l}\text { Low-gradient AS with left ventricular dysfunction but no } \\
\text { contractile reserve }\end{array}$ & $\mathrm{IIbC}$ & / \\
\hline
\end{tabular}

Table 2. Guidelines for aortic valve replacement in asymptomatic patients (Vahanian et al., 2007; Bonow et al., 2008). AVR is recommended in class I indications. AVR is reasonable in class IIa and may be considered in class IIb indications. Note that most indications are based only on a level of evidence C. EF denotes ejection fraction; CABG denotes coronary artery bypass grafting; $\mathrm{BP}$ denotes blood pressure; CAD denotes coronary artery disease; BAV denotes balloon aortic valvuloplasty. 
(low-gradient, low-flow AS) from those with a cardiomyopathy and concomitant only moderate AS. Dobutamin challenge for low-gradient aortic stenosis and left ventricular dysfunction may result in three pattern of responsiveness: fixed aortic stenosis, relative aortic stenosis and absence of contractile reserve. A fixed aortic stenosis is characterized by an increase in peak velocity $>4 \mathrm{~m} / \mathrm{s}$ and a mean systolic gradient $>40 \mathrm{mmHg}$ with no change in aortic valve area. These patients may still benefit from valve replacement despite increased perioperative rsik. In contrast, relative aortic stenosis is characterized by a significant increase in calculated aortic valve area $\left(>0.3 \mathrm{~cm}^{2}\right)$ without a significant increase in peak velocity or systolic gradients, whereas no variable changed significantly in patients without contractile reserve (lack of increase $>20 \%$ of stroke volume).

\subsection{Electrocardiogram}

Resting ECG in severe aortic stenosis usually shows signs of left ventricular hypertrophy, often accompanied by repolarisation abnormalities (ST-T-wave changes). Left ventricular hypertrophy is an independent predictor for the development of symptoms in asymptomatic severe aortic stenosis. However, the sensitivity for detecting left ventricular hypertrophy by the electrocardiogram is only $40 \%$ (Dal-Bianco et al., 2008). Conduction abnormalities are common ranging from first-degree atrio-ventricular block or bundle branch block. Atrial fibrillation is not a typical sign of aortic stenosis and may indicate concomitant mitral valve disease.

\subsection{Biomarkers}

Natriuretic peptides are secreted from the heart as response to pressure overload. Whereas atrial natriuretic peptide (ANP) is produced in the atria, B-type natriuretic peptide (BNP) is mainly derived from ventricular myocardium. Obviously, increased intraventricular pressure due to significant aortic stenosis is accompanied by elevated plasma levels of BNP and its derivatives such as N-terminal pro BNP. Such an elevation of natriuretic peptides predict adverse clinical outcome, such as occurrence of symptoms in still asymptomatic patients or higher operative mortality or worse post-operative outcome (Bergler-Klein et al., 2004; Pedrazzini et al., 2008). Systemic inflammation, expressed by elevated plasma CRP levels, influence the clinical outcome in advanced stages of aortic stenosis whereas no correlation to the progression from aortic sclerosis to aortic stenosis could be found in the Cardiovascular Health Study (Galante et al., 2001; Novaro et al., 2007).

\subsection{Exercise test}

An exercise test may be considered for patients with severe AS and equivocal symptoms or for asymptomatic, physically active patients with severe AS and slow progression. A stress test can unmask signs like dyspnoea, angina pectoris, and inadequate rise in blood pressure, complex ventricular arrhythmias or repolarisation abnormalities, and dizziness. Patients suffering from symptoms during exercise have an event-free survival rate of lower than $20 \%$ within 2 years, whereas patients with a normal exercise tolerance have a survival rate of over $80 \%$ at 5 years (Iung, 2011). A positive exercise test is associated with a 7 times higher clinical event rate (Amato et al., 2001).

The exercise test should be interrupted for limiting dyspnoea and fatigue, any angina or dizziness, $>2 \mathrm{~mm}$ ST depression, any decrease in systolic blood pressure $(>20 \mathrm{mmHg}$ or a fall compared to baseline), and complex ventricular ectopy. The exercise test should be 
considered abnormal if exercise tolerance is $<80 \%$ according to age- and sex-adjusted levels. The type of exercise test-induced symptom is important for the outcome. Patients with dizziness on exertion have an $83 \%$ probability for proximate developing of symptoms, whereas with breathlessness or chest tightness it is only $54 \%$, respectively $50 \%$ (Dal-Bianco et al., 2008).

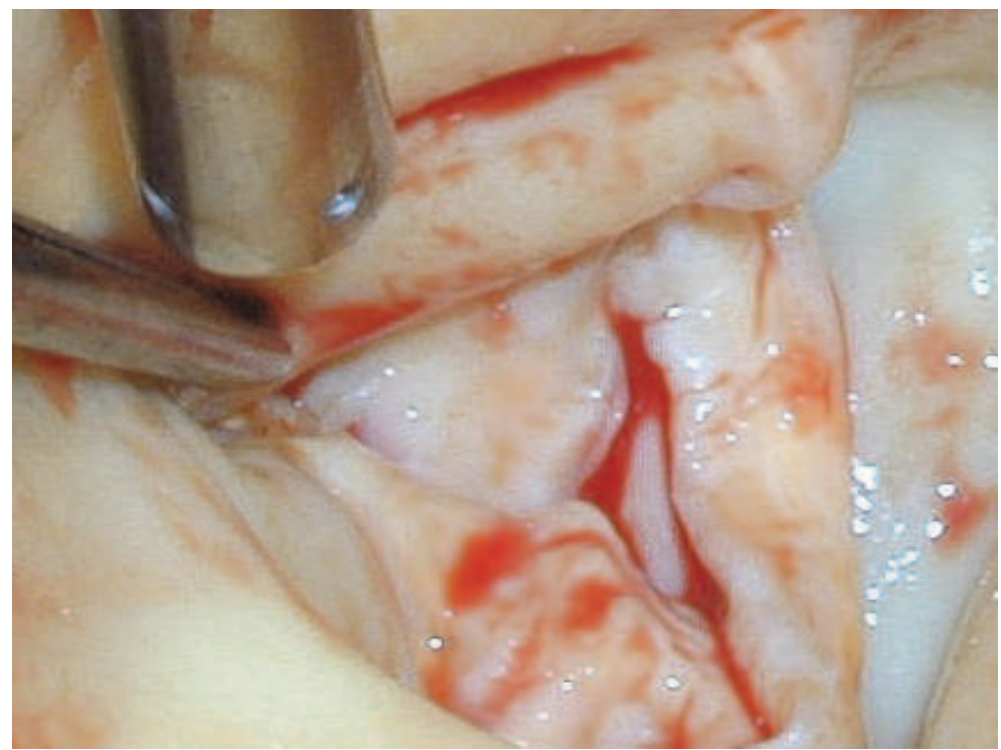

Fig. 5. Intraoperative view of a severely calcified and stenotic aortic valve.

\subsection{Cardiac catherization}

The role of invasive assessment of aortic stenosis severity has decreased in the last decades, mainly due to the diagnostic power of echocardiography. Passage through a stenotic valve may lead to peripheral embolism. The main indication of cardiac catherization is nowadays to perform coronary angiography at symptom onset. Multislice computed tomography may be used in young patients with a low probabilty of coronary artery disease instead, but this method is limited in older patients because of coronary calcification causing blooming artefacts. Using specific catheters, simultaneous evaluation of the proximal aortic and left ventricular pressures yields the most accurate data. It is important to distinguish the maximum instantenous gradient from the mean and peak-to-peak gradients, when comparing to echocardiographic measurements. Right heart catherization is often performed to assess cardiac output by either the Fick principle or the indicator dilution technique, which allows aortic valve area calculation by the Gorlin formula.

\subsection{Chest X-ray}

Poststenotic dilatation of the aorta ascendens is often the main chest $X$-ray finding in patients with aortic stenosis, whereas cardiac silhouette shows no or only minor enlargement. Calcification of the aortic valve is hardly seen on chest X-ray, in contrast to flouroscopy or electron-beam / multislice computed tomography (see below). 


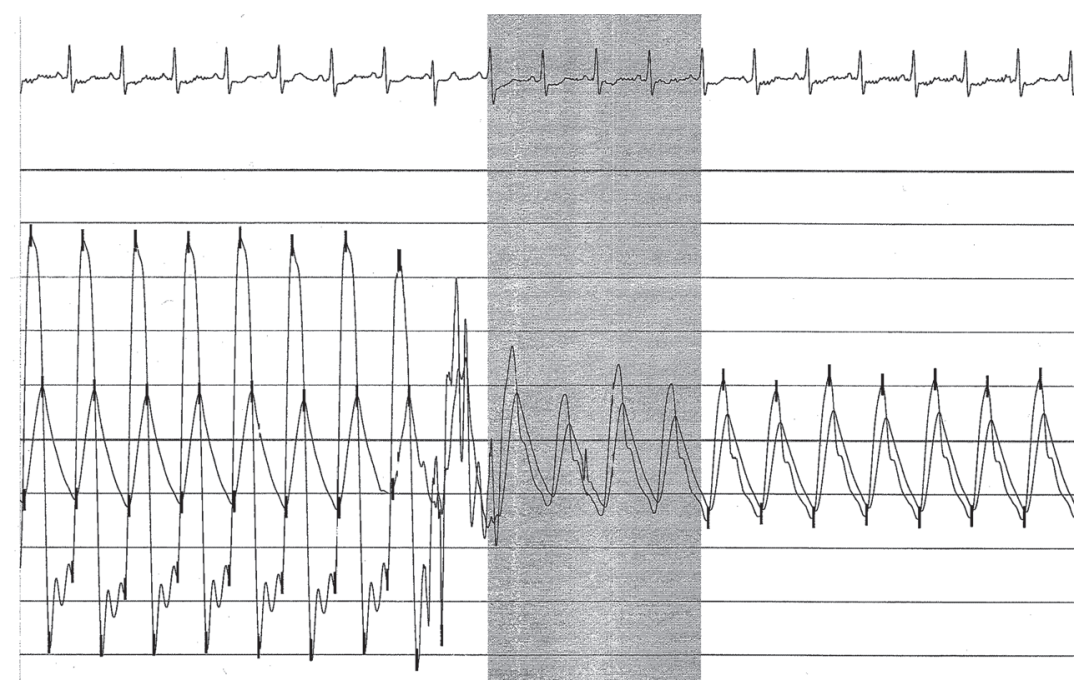

Fig. 6. Invasive assessment of aortic stenosis. Simultaneous measurement of left ventricular and aortic pressures (left side), showing a significant pressure gradient indicating severe aortic stenosis. This gradient disappears after pull-back of the tip of the catheter into the aorta ascendens (right side).

\subsection{Cardiac multislice computed tomography and cardiac magnetic resonance}

Although limited by the exposure to radiation, its availibity and its use in patients with high heart rate or atrial fibrillation, multislice computed tomography (MSCT) may be helpful in certain clinical situations in patients with aortic stenosis, e.g. diagnosis of coronary artery disease (Figure 3) or better assessment of aortic dilatation / aneurysm. Although lipidlowering therapy does not halt progression of moderate aortic stenosis, it is certainly indicated in the majority of patients because of concomitant coronary artery disease, as shown in the SEAS study and discussed below. MSCT is superior to quantify aortic valve calcification, although no cut-off point has been established yet influencing clinical decision making. It may also diagnose bicuspid valve morphology, and may even be helpful in assessment of valve area (Feuchtner et al., 2006). Cardiac MRI has been used in patients with asymptomatic aortic stenosis as well, but is not suitable for detection of concomitant coronary disease. Both MSCT and MRI have the limitation that they measure the anatomic and not the functional effective AVA, so the AS severity is often underrated. The velocity- encoded phase contrast imaging is a new magnetic resonance imaging technique, which allows aortic valve area quantification with the continuity equation imitating echocardiographic Doppler quantification. It is helpful in patients with poor echochardiographic windows, obesity, lung disease, or heavily calcified aortic valve (Dal-Bianco et al., 2008).

\section{Clinical issues in asymptomatic aortic stenosis}

\subsection{Prognosis}

The natural history of asymptomatic patients with moderate to severe aortic stenosis is not benign. One half of patients with mild-to-moderate aortic stenosis develop severe outflow 


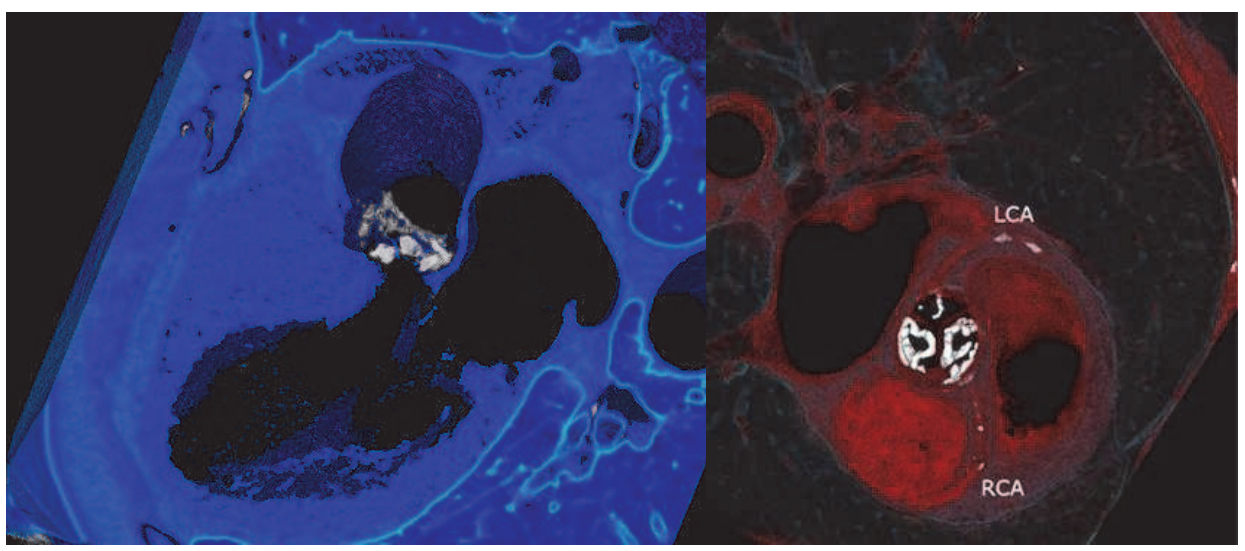

Fig. 7. Cardiac MSCT showing severe aortic valve calcification. On the left panel, poststenotic dilatation of the ascending aorta can be seen, whereas concomitant coronary artery calcification can be detected on the right panel. LCA denotes left coronary artery; RCA denotes right coronary artery.

obstruction within 6 years (Rosenhek et al., 2004). A large prospective study of asymptomatic patients with severe aortic stenosis showed that freedom from cardiovascular death or aortic valve replacement at 1, 2 and 5 years were only $80 \%, 63 \%$ and $20 \%$, respectively. (Pellikka et al., 2005). This is particularly true for patients with very severe aortic stenosis, whose eventfree survival is only $64 \%, 36 \%, 25 \%$ and $12 \%$ at 1, 2, 3 and 4 years, respectively (Rosenhek et al., 2009). Furthermore, patients with a peak systolic velocity $>5.5 \mathrm{~m} / \mathrm{s}$ not referred to elective surgery present with severe symptom onset (defined by NYHA functional class $>$ II), which is associated with a worse perioperative outcome.

A survival analysis from 1968 from Ross and Braunwald showed that patients with aortic stenosis who had developed angina and syncope survived 3 years, patients with dyspnoea 2 years, and patients with heart failure survived only 1 to 2 years. This study included symptomatic patients with heterogeneous AS etiology, thus not only calcific aortic stenosis.

\subsection{Noncardiac surgery risk}

Aortic stenosis is a risk factor for perioperative mortality and nonfatal myocardial infarction, but it is unclear whether aortic valve surgery should precede noncardiac surgery. Complication rates are depending on the severity of aortic stenosis and the type of noncardiac surgery performed. Perioperative complications may occurr in up to $11 \%$ of patients with moderate aortic stenosis and $31 \%$ of patients with severe aortic stenosis, as compared to $2 \%$ in matched patients without aortic stenosis (Kertai et al., 2004). In experienced centers, low or intermediate risk noncardiac surgery can be performed safely even in patients with severe asymptomatic aortic stenosis with a low myocardial infarction rate of around 3\%, if there is prompt vasopressor therapy for hypotensive episodes (Calleja et al., 2010).

\subsection{Endocarditis prophylaxis}

In 2009, the ESC guidelines concerning antibiotic endocarditis prophylaxis have changed limiting its use to only high-rik patients, such as patients with prosthetic valves, previous infective endocarditis or certain congenital heart disease. Degenerative aortic stenosis is not 
an indication for antibiotic endocarditis prophylaxis, even if a bicuspid aortic valve is present (Habib et al., 2009).

\subsection{Aggressive cardiovascular risk factor intervention}

As mentioned above, arterial hypertension puts additional load to the left ventricle in patients with aortic stenosis, and should be carefully treated. However, hypotensive episodes have to be avoided, and regular blood pressure measurements are mandatory. Retrospective studies suggested that lipid-lowering with statins might slow the progression of aortic stenosis, but prospective studies such as SALTIRE (Cowell et al., 2005) or SEAS (Rossebo et al., 2008) could not confirm such a positive effect on aortic valve events in patients with a LDL cholesterol below $140 \mathrm{mg} / \mathrm{dl}$. Nevertheless, the majority of the patients with aortic stenosis need statins because of three reasons:

- concomitant coronary artery disease: in SEAS, intensive lipid-lowering therapy with simvastin $40 \mathrm{mg}$ and ezetimibe $10 \mathrm{mg} / \mathrm{d}$ daily reduced cardiovascular ischemic events even in patients with baseline LDL cholesterol below $140 \mathrm{mg} / \mathrm{dl}$, mainly driven by a significant reduction in the need of additional bypass grafting when aortic valve replacement became mandatory; notably, LDL cholesterol were reduced by $61.3 \%$ to mean $55 \mathrm{mg} / \mathrm{dl}$.

- hypercholesterolemia: RAAVE, the only prospective study showing a slowing effect on the hemodynamic progression of aortic stenosis, was performed in hypercholesterolemic patients, defined by a LDL cholesterol above $160 \mathrm{mg} / \mathrm{dl}$ (Moura et al., 2007); therefore, such patients should receive statin therapy.

- early stage of the disease: a retrospective analysis of 1046 patients (Antonini-Canterin, et al., 2008) could show that statin therapy slowed hemodynamic progression in the early stages of the disease process, e.g. aortic sclerosis or mild aortic stenosis. However, this effect disappeared in patients with more advanced aortic stenosis (defined by a baseline peak aortic velocity between 3 and $4 \mathrm{~m} / \mathrm{s}$ ).

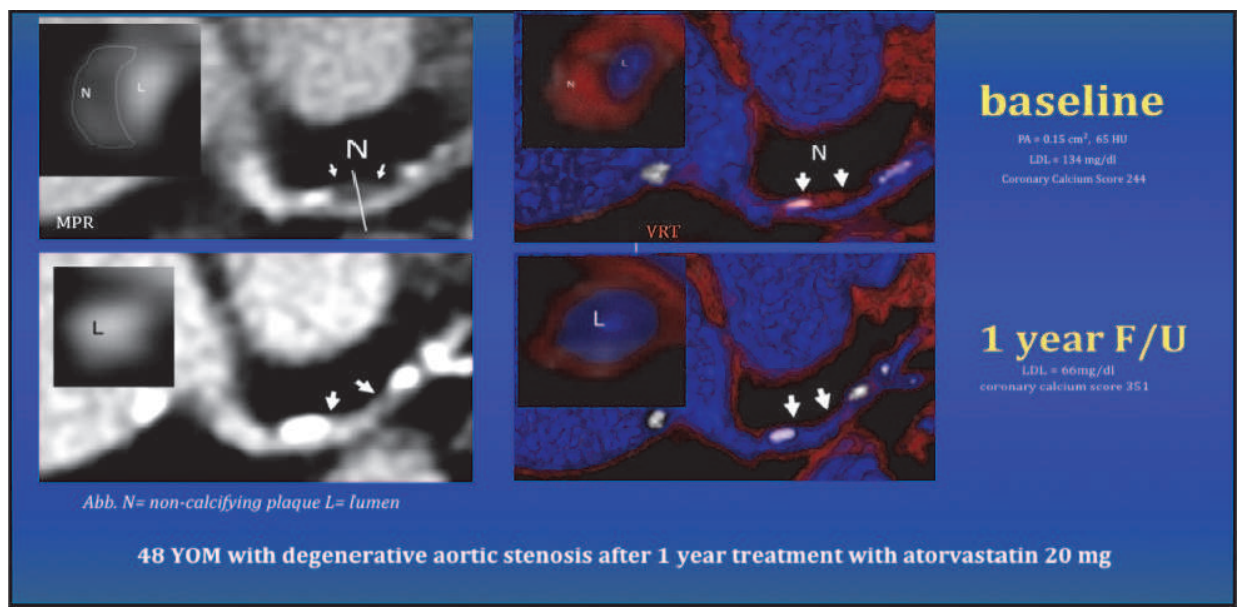

Fig. 8. Cardiac MSCT examinations showing the effects of newly initiated statin treatment on concomitant coronary artery disease. MPR denotes multiplanar reformation; VRT denotes volume-rendering technique; $\mathrm{N}$ denotes non-calcified atherosclerotic plaque; $\mathrm{YOM}$ denotes year old man. 


\subsection{Recommended intervals for follow-up examinations}

For asymptomatic patients with aortic stenosis, close follow-up is imperative. Clinical evaluation should be performed once a year in patients with mild or moderate aortic stenosis and every 6 months in patients with severe aortic stenosis. Patients need to be questioned thoroughly about symptoms and exercise levels, along with the assessment and treatment of cardiovascular risk factors. Any change in symptoms should prompt the physician to perform a transthoracic echocardiography. Otherwise, intervals between echocardiography examinations are 3 - 5 years in patients with mild aortic stenosis, 1 - 2 years in patients with moderate aortic stenosis and 6 months to 1 year in patient with severe stenosis. In patients with severe asymptomatic aortic stenosis, exercise testing and measurement of natriuretic peptide levels may be helpful.

\subsection{Bicuspid aortic valve disease}

Bicuspid aortic valve is the most common inherited valve abnormality, affecting $1-2 \%$ of all individuals. There is a genetic component which may justify familiy testing. Around $40 \%$ of patients with bicuspid Aortic valves often suffer from dilatation of the ascending aorta as well, independent of the severity of aortic stenosis and/or insufficiency. A major risk of aortic dilation in these patients is aortic dissection, being 9 times higher for patients with a bicuspid aortic valve than for patients with a tricuspid valve. If the maximum diameter is $\geq 5 \mathrm{~cm}$ with a fast progression rate above $0.5 \mathrm{~cm}^{2} /$ year, surgery may be considered even in asymptomatic patients (Class IIaC indication according to ESC guidelines). Therefore, echocardiography should always include measurement of the diameter of the ascending aorta. If dilatation predominates above the sinotubular junction, diagnosis can be missed by transthoracic echocardiography and additional imaging techniques should be considered. Otherwise, management of bicuspid aortic valve disease is similar to that of tricuspid valve disease.

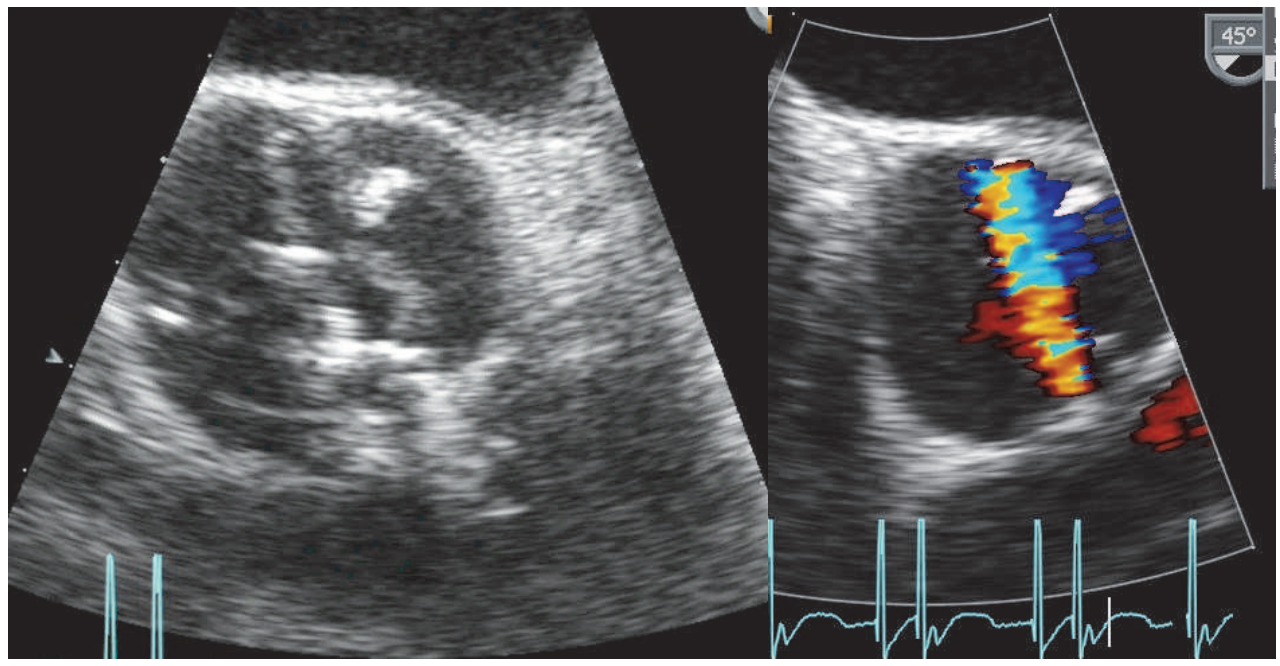

Fig. 9. Using transesophageal echocardiography in a patient with calcific aortic stenosis, a biscupid valve morphology is detected and planimetry of the aortic valve area can be reliably performed. 

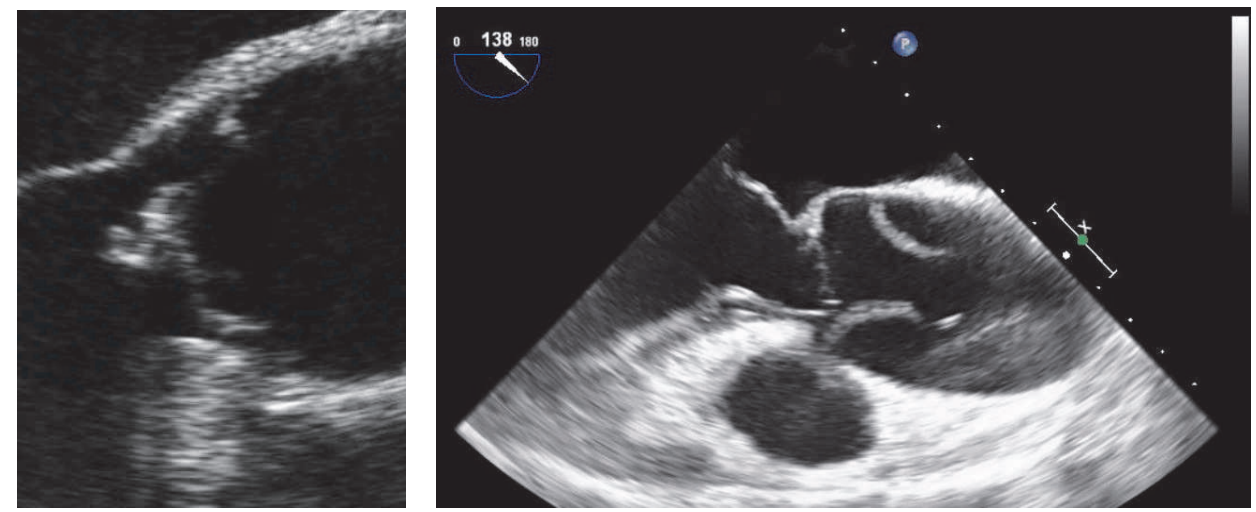

Fig. 10. Complications associated with bicuspid aortic valve disease: endocarditis (left panel) and acute aortic dissection (right panel).

\subsection{Balancing risks between earlier surgery and watchful waiting}

Besides a positive exercise test, no single risk factor is an absolute criterion to predict poor clinical outcome in patients with asymptomatic severe aortic stenosis so far. Other indicators of high-risk such as rapid hemodynamic progression, heavy valve calcification or increased natriuretic peptide levels should be weightened against the risk of surgery.

Fortunately, operative risk of isolated aortic valve replacement has dramatically declined over the last decades, currently being $2-5 \%$ in patients $<70$ years and $5-15 \%$ in patients above 70 years. Concomitant bypass surgery increases the perioperative risk by around $5 \%$. The EuroSCORE or the Society of Thoracic Surgeons predicted risk of mortality (STSPROM) score are commonly used for the evaluation of the preoperative risk for cardiac surgery. The simple additive EuroSCORE model is easy to use, even at the bedside. In high risk patients, however, the simple additive model often underestimates the risk when certain combinations of risk factors co-exist, and the logististic EuroSCORE should be used. It takes into consideration age, sex, chronic pulmonary disease, extracardiac arteriopathy, neurological dysfunction, previous cardiac surgery, renal insufficiency, active endocarditis, critical preoperative state, as well as cardiac-related factors such as unstable angina, left ventricular function, recent myocardial infarction and pulmonary hypertension.

If a watchful waiting strategy is chosen, the patient should be educated and advised to selfreport onset of new symptoms to physician immediately. Patients often reduce subconsciously their physical activity, and so only a stress testing can uncover symptoms.

\subsection{The comorbid and elderly patient - considerations on transcatheter aortic valve implantation}

A third of patients with severe symptomatic aortic stenosis are not referred for valve replacement. This is mainly a problem for elderly patients, because many physcians ignore the fact that age itself is not a contra-indication to aortic valve implantation. The EuroSCORE or the STS-PROM score are commonly used to estimate the preoperative risk for cardiac surgery. Both scores incorporate various comorbidities such as chronic pulmonary disease and renal insufficiency; if a patient has too grave comorbidities he might be deemed inoperable. The approach to comorbid symptomatic patients is solid risk evaluation in experienced medical centers with a high surgery volume ("heart team"). 
Interventional cardiologist more and more challenge heart surgeons by the introduction of transcatheter aortic valve implantation (TAVI), and the years to come will show if this new procedure may play a role also in younger patients with moderate preoperative risk.

On the basis of current clinical outcome data, for symptomatic patients with severe aortic stenosis and a life expectancy over 1 year, indications for TAVI are definite contraindications to surgery or when surgery is estimated very high risk and if there are no barriers to TAVI.

The results of TAVI are preliminary and any conclusions carry limitations. It seems that TAVI is practicable and present acceptable clinical and hemodynamic results up to 3 years. However, there are still major limitations for TAVI, e.g. paravalvular leaks causing significant aortic insufficiency, a higher postoperative need for pacemaker implantation or vascular complications. Bicuspid aortic valve morphology is not suitable for TAVI as well. The access for transcatheter aortic valve implantation is retrograde via the femoral or the subclavian artery or antegrade through a transapical approach.

\section{Conclusions}

Besides coronary artery disease and arterial hypertension, aortic stenosis is the third most common cardiovascular disorder in the Western World, affecting more than four percent of the population above 75 years. It is easy to diagnose by auscultation and subsequent transthoracic echocardiography. Surgical aortic valve implantation (SAVI) offers a very good therapeutic option for symptomatic patients with severe valve obstruction which has a dismal prognosis if left untreated. In contrast, the decision to operate on asymptomatic patients remains a controversity. Unfortunately, there is still no medical therapy available to prevent the development or to delay the progression of aortic stenosis. Probably, medical intervention would be most effective in early stages of the disease, even before obstruction of the left ventricular outflow occurs. This condition called aortic sclerosis is present in $25 \%$ of adults over 65 years of age. Currently, around 15\% of these patients progress to hemodynamically significant aortic stenosis, and it would be of great importance to stop this active process more effectively in these patients.

\section{Acknoledgment}

The authors thank Dr. Gudrun Feuchtner, Dr. Hannes Alber and Dr. Maria Wanitschek for support in preparation of Figures 6-8.

\section{References}

Antonini-Canterin, F.; et al. (2008). Stage-Related Effect of Statin Treatment on the Progression of Aortic Valve Sclerosis and Stenosis. American Journal of Cardiology, 102, pp. 738-742.

Amato, MCM.; et al. (2001). Treatment Decision in Asymptomatic Aortic Valve Stenosis: Role of Exercise Testing. Heart, 86, pp. 381-386.

Bergler-Klein, J.; et al. (2006). Natriuretic Peptides Predict Symptom-Free Survival and Postoperative Outcome in Severe Aortic Stenosis. Circulation, 109, pp. 2302-2308, ISSN 0009-7322. 
Bermejo, J.; et al. (2003). Clinical Efficacy of Doppler-Echocardiographic Indices of Aortic Valve Stenosis: A Comparative Test-Based Analysis of Outcome. Journal of the American College of Cardiology, 41, pp. 142-149.

Bonow, RO.; et al. (2008). 008 Focused Update Incorporated Into the ACC/AHA 2006 Guidelines for the Management of Patients With Valvular Heart Disease: A Report of the American College of Cardiology/American Heart Association Task Force on Practice Guidelines. Journal of the American College of Cardiology, 52, pp. e1-142.

Calleja, AM.; et al. (2010). Cardiac Risk in Patients Aged > 75 Years With Asymptomatic, Severe Aortic Stenosis Undergoing Noncardiac Surgery. American Journal of Cardiology, 105(8), pp. 1159-1163.

Cowell, SJ.; et al. (2005). A Randomized Trial of Intensive Lipid-Lowering Therapy in Calcific Aortic Stenosis. New England Journal of Medicine, 352, pp. 2389-2397.

Dal-Bianco, JP.; et al. (2008). Management of Asymptomatic Severe Aortic Stenosis. Journal of the American College of Cardiology, 52, pp. 1279-1292, ISSN 0735-1097.

Feuchtner, GM.; et al. (2006). Multislice Computed Tomography for Detection of Patients With Aortic Valve Stenosis and Quantification of Severity. Journal of the American College of Cardiology, 47, pp. 1410-1417.

Galante, A.; et al. (2001). C-Reactive Protein is Increased in Patients with Degenerative Aortic Valvular Stenosis. Journal of the American College of Cardiology, 38, pp. 10781082.

Habib, G.; et al. (2009). Guidelines on the Prevention, Diagnosis, and Treatment of Infective Endocarditis. European Heart Journal, 30, pp. 2369-2413.

Iung, B. (2011). Management of Asymptomatic Aortic Stenosis. Heart, 97, pp. 253-259.

Kertai, MD. et al. (2004). Aortic Stenosis: An Underestimated Risk Factor For Perioperative Complications In Patients Undergoing Noncardiac Surgery. American Journal of Medicine, 116, pp. 8-13.

Monin, JL.; et al. (2009). Risk Score for Predicting Outcome in Patients With Asymptomatic Aortic Stenosis. Circulation, 120, pp. 69-75, ISSN 0009-7322.

Moura, LM.; et al. (2007). Rosuvastatin Affecting Aortic Valve Endothelium to Slow the Progression of Aortic Stenosis. Journal of the American College of Cardiology, 49, pp. $554-561$.

Novaro, GM.; et al. (2007). Clinical Factors, But Not C-Reactive Protein, Predict Progression of Calcific Aortic-Valve Disease. Journal of the American College of Cardiology, 50, pp. 1992-1999, ISSN 0735-1097.

Pedrazzini, GB.; et al. (2008). Comparison of Brain Natriuretic Peptide Plasma Levels Versus Logistic EuroSCORE in Predicting In-hospital and Late Postoperative Mortality in Patients Undergoing Aortic Valve Replacement for Symptomatic Aortic Stenosis. American Journal of Cardiology, 102, pp. 749-754.

Pellikka, PA.; et al. (2005). Outcome of 622 Adults With Asymptomatic, Hemodynamically Significant Aortic Stenosis During Prolonged Follow-up. Circulation, 111, pp. 32903295.

Rosenhek, R.; et al. (2004). Mild and Moderate Aortic Stenosis. Natural History and Risk Stratification By Echocardiography. European Heart Journal, 25, pp. 199-205.

Rosenhek, R.; et al. (2009). Natural History of Very Severe Aortic Stenosis. Circulation; 121, pp. 151-156, ISSN 0009-7322.

Ross, J Jr. \& Braunwald, E. (1968). Aortic Stenosis. Circulation; 38, pp. 61-67. 
Rossebo, AB.; et al. (2008). Intensive Lipid Lowering with Simvastatin and Ezetimibe in Aortic Stenosis. New England Journal of Medicine, 359, pp. 1343-1356.

Vahanian, A.; et al. (2007). Guidelines on the Management of Valvular Heart Disease. The Task Force on the Management of Valvular Heart Disease of the European Society of Cardiology. European Heart Journal, 28, pp. 230-268.

Vahanian, A. \& Otto, CM. (2010). Risk Stratification of Patients With Aortic Stenosis. European Heart Journal, 31, pp. 416-423. 


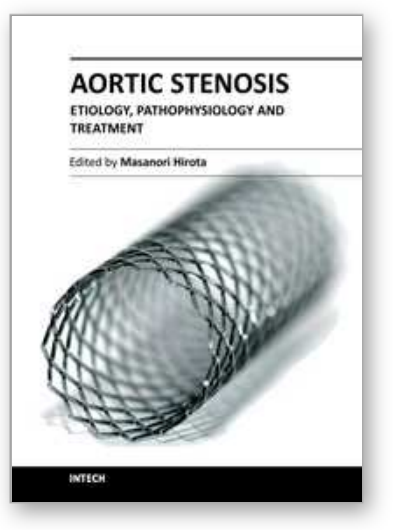

\author{
Aortic Stenosis - Etiology, Pathophysiology and Treatment \\ Edited by Dr. Masanori Hirota
}

ISBN 978-953-307-660-7

Hard cover, 254 pages

Publisher InTech

Published online 10, October, 2011

Published in print edition October, 2011

Currently, aortic stenosis (AS) is the most prevalent valvular disease in developed countries. Pathological and molecular mechanisms of AS have been investigated in many aspects. And new therapeutic devices such as transcatheter aortic valve implantation have been developed as a less invasive treatment for high-risk patients. Due to advanced prevalent age of AS, further discovery and technology are required to treat elderly patients for longer life expectancy. This book is an effort to present an up-to-date account of existing knowledge, involving recent development in this field. Various opinion leaders described details of established knowledge or newly recognized advances associated with diagnosis, treatment and mechanism. Thus, this book will enable close intercommunication to another field and collaboration technology for new devices. We hope that it will be an important source, not only for clinicians, but also for general practitioners, contributing to development of better therapeutic adjuncts in the future.

\title{
How to reference
}

In order to correctly reference this scholarly work, feel free to copy and paste the following:

Paoli Ursula and Dichtl Wolfgang (2011). Asymptomatic Aortic Stenosis - Prognosis, Risk Stratification and Follow-Up, Aortic Stenosis - Etiology, Pathophysiology and Treatment, Dr. Masanori Hirota (Ed.), ISBN: 978953-307-660-7, InTech, Available from: http://www.intechopen.com/books/aortic-stenosis-etiologypathophysiology-and-treatment/asymptomatic-aortic-stenosis-prognosis-risk-stratification-and-follow-up

\section{INTECH}

open science | open minds

\section{InTech Europe}

University Campus STeP Ri

Slavka Krautzeka 83/A

51000 Rijeka, Croatia

Phone: +385 (51) 770447

Fax: +385 (51) 686166

www.intechopen.com

\section{InTech China}

Unit 405, Office Block, Hotel Equatorial Shanghai

No.65, Yan An Road (West), Shanghai, 200040, China

中国上海市延安西路65号上海国际贵都大饭店办公楼 405 单元

Phone: +86-21-62489820

Fax: $+86-21-62489821$ 
(C) 2011 The Author(s). Licensee IntechOpen. This is an open access article distributed under the terms of the Creative Commons Attribution 3.0 License, which permits unrestricted use, distribution, and reproduction in any medium, provided the original work is properly cited. 